\title{
KEY ASPECTS OF MATURITY ASSESSMENT IN LEAN CONSTRUCTION
}

\author{
Sandra Cano ${ }^{1}$, Luis Botero ${ }^{2}$, Jorge Luis García-Alcaraz ${ }^{3}$, \\ Rafael Tovar $^{4}$, and Leonardo Rivera ${ }^{5}$
}

\begin{abstract}
To achieve Lean Construction maturity in the management of the construction project is a continuous improvement process that occurs when the LC implementation is integrated into the life cycle of the construction project. The model for the evolution of Lean Construction maturity in the production management of construction projects, the SLCEM model, contains the standard with which each of the elements involved in the maturity of Lean Construction (LC) is evaluated in construction project management (CPM). Identifying the elements that show the extent of maturity and understanding how they relate is the main task for the development of the SLC-EModel. When evaluating the maturity elements, the local and global maturity indices explain the maturity of the CPM system. The indices are external references to start a cycle of continuous improvement for the evolution towards a higher level of maturity. This research presents a maturity assessment model and an evolution strategy to advance towards the highest possible level of LC maturity in the management of construction projects.
\end{abstract}

\section{KEYWORDS}

Assessment, Evolution, Lean construction, Maturity, Maturity model.

\section{INTRODUCTION}

The low productivity of the construction industry compared to other sectors, which is caused by different conditions associated with the production process, is caused by problems that improve with the implementation of LC (Bashir, Suresh, Proverbs, and Gameson 2011). Among these problems are: lack of transparency, coordination, and communication between the actors involved, low quality, the generation of unforeseen errors, the lack of adequate distribution of information, industrial insecurity, and corruption. (Bashir, Suresh, Proverbs, and Gameson, 2011).

1 Prof., Escuela de Ingeniería Civil y Geomática, Universidad del Valle, Calle 13 No 100-00 edificio E48. Cali, Colombia, +(57) (2) 3212100 ext. 7231, sandra.cano@correounivalle.edu.co, orcid.org/0000-0003-4257-6035

2 Prof., Departamento de Ingeniería Civil, Universidad de Eafit, Carrera 49 \# 7 sur - 50. +(57) (4) 2619500 Ext 9659, Medellín, Colombia, 1fbotero@eafit.edu.co, orcid.org/0000-0003-3418-7144

3 Prof., Departamento de Ingeniería Industrial y Manufactura, Universidad Autónoma de Ciudad Juárez, México, jorge.garcia@uacj.mx, orcid.org/0000-0002-7092-6963

4 Prof., Escuela de Estadística, Universidad del Valle, Calle 13 No 100-00 edificio E56. Cali, Colombia, +(57) (2) 3212100 ext. 7231, jose.r.tovar@correounivalle.edu.co, orcid.org/0000-0003-0432-4144

5 Prof., Escuela de Ingeniería Industrial, Universidad del Valle, Cali, Colombia, Calle 13 No 100-00 edificio E56, Cali, Colombia, leonardo.rivera.c@,correounivalle.edu.co, orcid.org/0000-0001-9942$\underline{5188}$ 
The implementation of LC should be carried out systematically according to a specific route, guided by the influence of the elements that contribute to reaching the maturity of the construction project production system (CPPS). An implementation path can be driven by a maturity model. This article presents part of the doctoral research to obtain the "Lean Construction Maturity Evolution Model in Construction Project Production Management," the SLC-EModel, (Cano, 2019). This research consulted papers of LC assessment reported in scientific databases and 171 people related to LC in 19 countries. Focus groups, interviews, and surveys were applied for the identification of the elements associated with the maturity of LC in the CPM. As a result, 450 items were identified (these elements are the characteristics related to LC maturity).

These 450 elements were grouped into three categories, seven factors, and 35 attributes. The categories are People who support the production of construction projects, Construction project production system, and Support of the production organization. Attributes are variables that can be directly measured; therefore, they were the object of a survey to about by their importance in the maturity of LC. This evaluation is fundamental for model construction. A multivariate method is applied to establish the correlation between the attributes for the development of the model. The Structural Equations Model (SEM) allowed to group the attributes into maturity factors and to identify the relationships between them. The connections are quantitatively identified and expressed as equations. Equations are assembled to obtain a mathematical maturity expression that qualifies the maturity of the system from the maturity of the factors in the SLC-EModel.

\section{LEAN MATURITY IN CPM}

Construction organizations develop their commercial activity through construction projects, and the CPM is their most relevant process. Construction companies around the world have been integrating LC into the CPM because of the benefits it offers for greater efficiency. Similarly, there is an increasing interest in knowing the extent of the maturity of LC and introducing improvements to the production system to reach a higher efficiency. It is essential to begin by understanding aspects related to the implementation and maturity of LC in the CPM to drive the use of a model like the SLC-EModel as an evaluation and evolution tool towards higher levels of maturity.

Some of the experts who were consulted, highlight that it is still too early to talk about the existence of mature construction organizations in LC. They recognize that some construction organizations have high levels of LC implementation. In general, the construction project shows few developments in its production phases, especially in the construction phase, which generates the highest consumption of resources, by the little attention paid to production flow management activities (Vieira, 2006). Although many construction companies are transitioning to an LC production system as a strategy to improve their productivity (Costa Neto et al., 2015), this transition requires precise routes to effectively direct implementation efforts.

\section{DEFINITION OF MATURITY}

Nesensohn (2014) discusses the concept of maturity in the organizational and project context-based definitions studied. It synthesizes that maturity is a concept that is used in different management contexts: the maturity of the organization, the maturity of project management, and the maturity of the process. In this way, he agrees with Andersen and Jessen, (2003) that the maturity of project management "is the ability of the organization 
to handle different types of projects effectively and efficiently, while achieving the objectives of the project" ( p. 457).

Following the above, it is possible to differentiate between the organization's maturity and project maturity; then, project maturity could be achieved independently of the maturity of the organization. This research proposes that the definition of maturity includes concepts such as the ability to develop, evaluate, sustain, and continuously improve a standard for a process. We propose the following definition.

\section{DEFINITION}

Maturity is the state of maximum development, or state of excellence, that offers the ability to make the projected objective come true with the most efficient use of available resources. It is a state that is gradually reached by going through different levels of maturity, which allow us to escalate towards a maximum standard, a reference level of excellence for the context, a "Gold Standard." (Cano and Rivera, 2015).

\section{Maturity ASSESSMENT}

Maturity is assessed with tools specifically designed for this purpose as maturity models. These models contain a set of processes organized at maturity levels that must be progressively achieved. According to Ibbs and Kwak (2000), the usefulness of maturity models in the field of project management is to promote better project performance. So "PM's maturity is a well-defined level of sophistication that evaluates the current practices and processes of project management of an organization" (p. 1) also, a tool for maturity assessment must offer specific implementation paths.

The maturity model makes it possible to have comparative information that can be used to draw up an organizational improvement plan by identifying the strengths and weaknesses of the organization regarding its process areas (Ramirez, 2009). There is a wide variety of maturity models in different sectors. The best known is the Capability Maturity Model Integration (CMMI), which has been taken as a reference for the development of some maturity models such as SPICE (Ehsan, Perwaiz, Arif, Mirza, and Ishaque, 2010).

\section{Utility Of The Maturity Models}

The Maturity Models (MM) assess the maturity of elements in the process to determine the maturity level reached by the system. This assessment is represented by maturity levels. The evaluation of the capacities of elements is checked to maintain consistent performance over time and is used for the improvement in the process in which it seeks to mature. The MM are practical references that help organizations measure the point where they are on the road to excellence. This application is possible by analyzing and reducing the competitiveness gap in issues such as productivity and effectiveness from the development of best-referenced practices to achieve a differentiated, sustainable, and innovative value offer.

\section{ELEMENTS RELATED TO THE MATURITY OF LC}

The elements involved in the maturity of LC are identified from an exhaustive review of academic references on different initiatives to evaluate LC and primary information obtained from experts in LC consulted in the development of this research. The identified elements are grouped into Maturity Factors (FM), which constitute the maturity categories Figure 1. 
Maturity attributes are associated with each FM, nine attributes to the category "People who support the production of construction projects", 13 attributes to the category "Production system", and 13 attributes to category "Organization support to the production process of construction projects", Table 1.

\section{RELATIONS BETWEen MATURITY ElEMENTS}

In our model, maturity is a condition that is explained by latent variables or constructs. These are the FMs in this model. The FMs require measuring attributes directly related with them to be explained as a complete concept. Hypotheses are proposed about relations that involve the FMs to define the system maturity, which is tested with the help of a Structural Equations Model (Cupani, 2012) (García, 2011) (Chandra, 2015). The SEM is a technique that makes use of multiple regression and factor analysis with which complex dependency interrelationships are evaluated (Cupani 2012). For the evaluation of the maturity of LC in the CPM, statistical methods such as Principal Component Analysis, Factorial Analysis, Multiple Regression and Path Analysis are used, which allow the FM to be distinguished and operated from the correlation between the attributes responsible for the maturity.

The SEM is composed of two submodels: the measurement model, or Outer Model, and the structural or Inner Model. The Outer Model establishes the correlation between FMs and their attributes to explain or identify FMs, and take orders the rules of factor analysis (high correlation values indicate that the attributes describe the FM (Weston and Gore 2006). The Inner Model explains the relationships between FMs; it makes use of multivariate techniques such as multiple regression, factor analysis, and path analysis. The hypotheses proposed by researchers and experts on the evaluation of maturity are reflected in the suggested SEM. This SEM is tested and evaluated at its level of adjustment. The information to build the SEM is obtained from the application of a survey to 111 professionals related to the implementation of LC: professionals, researchers, consultants, academics, process managers, and senior management professionals responsible for LC. This survey indicated the importance of 48 measurable LC maturity attributes in previously selected construction projects to choose 35 model attributes. The sample obtained is statistically representative for inferring the behavior of the process under study.

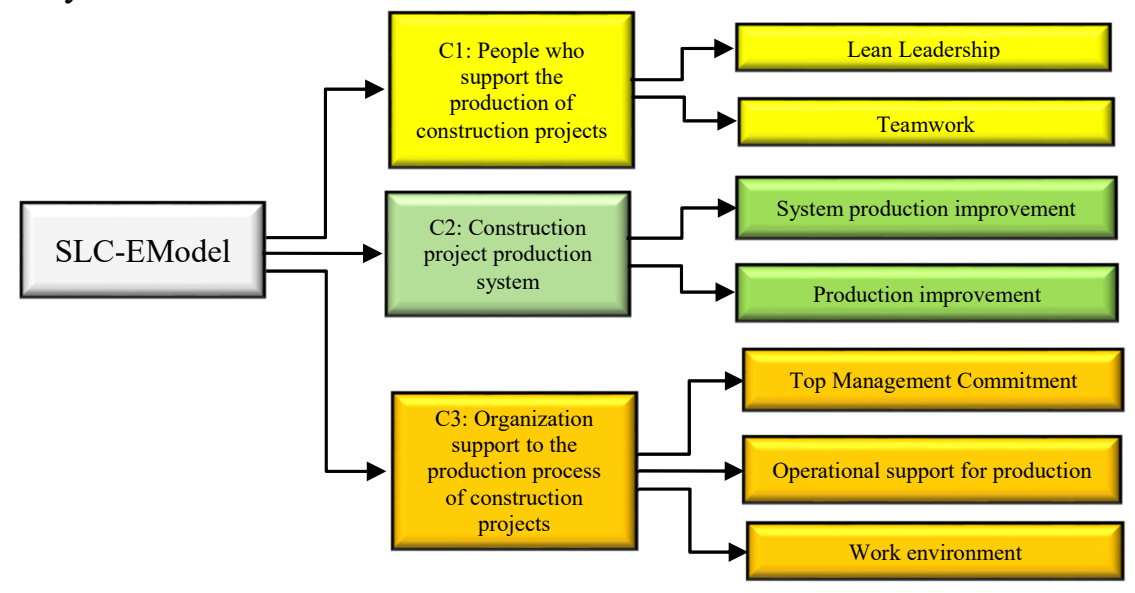

Figure 1: Elements of the SLC-EModel 
Table 1: Categories, factors, and attributes of maturity model

\begin{tabular}{|c|c|c|c|c|c|}
\hline \multicolumn{6}{|c|}{ Category: People who support the production of construction projects } \\
\hline \multicolumn{3}{|c|}{ Factor: Lean Leadership (LeaderSh) } & \multicolumn{3}{|c|}{ Factor: TeamWork (TeamWork) } \\
\hline \multirow{5}{*}{ 莣 } & $\mathrm{X}_{19}$ & Training in LC philosophy & \multirow{5}{*}{ 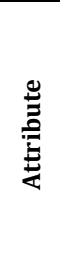 } & $\mathrm{X}_{1}$ & $\begin{array}{l}\text { Promotion and development of Lean } \\
\text { Construction }\end{array}$ \\
\hline & $\mathrm{X}_{20}$ & Lean culture & & $\mathrm{X}_{2}$ & Problem solving and continuous learning \\
\hline & $\mathrm{X}_{21}$ & Development of Lean leaders & & $\mathrm{X}_{3}$ & Teamwork processes \\
\hline & \multirow[t]{2}{*}{$\mathrm{X}_{22}$} & \multirow[t]{2}{*}{ Values and personal vision } & & $\mathrm{X}_{4}$ & Work team development \\
\hline & & & & $\mathrm{X}_{5}$ & Promotion of continuous improvement \\
\hline \multicolumn{6}{|c|}{ Category: Construction project production system } \\
\hline \multicolumn{3}{|c|}{ Factor: System Production Improve (SPImprov) } & \multicolumn{3}{|c|}{ Factor: Production Improvement (ProImpr) } \\
\hline \multirow{7}{*}{ 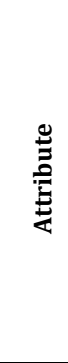 } & $\mathrm{X}_{23}$ & Flexibility & \multirow{7}{*}{ 总 } & $\mathrm{X}_{30}$ & Standards development \\
\hline & $\mathrm{X}_{24}$ & Cycle time reduction & & $\mathrm{X}_{31}$ & $\begin{array}{l}\text { Knowledge and selection of Lean } \\
\text { Construction tools }\end{array}$ \\
\hline & $\mathrm{X}_{25}$ & Variability Reduction & & $\mathrm{X}_{32}$ & Continuous flow \\
\hline & $\mathrm{X}_{26}$ & Complete process control & & $\mathrm{X}_{33}$ & Value offer fulfillment \\
\hline & $\mathrm{X}_{27}$ & Process simplification & & $\mathrm{X}_{34}$ & Development of a pull system \\
\hline & $\mathrm{X}_{28}$ & Transparency & & $\mathrm{X}_{35}$ & Continuous improvement \\
\hline & $\mathrm{X}_{29}$ & Benchmarking & & & \\
\hline \multicolumn{6}{|c|}{ Category: Organization support to the production process of construction projects } \\
\hline \multicolumn{3}{|c|}{ Factor: Top Management Commitment (CommTM) } & \multicolumn{3}{|c|}{ Factor: Operative Support for the Production (SupporOp) } \\
\hline \multirow{4}{*}{ 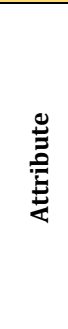 } & $\mathrm{X}_{9}$ & $\begin{array}{l}\text { Definition and deployment of } \\
\text { the policy and strategy to } \\
\text { support Lean construction }\end{array}$ & \multirow{6}{*}{ 莣 } & $\mathrm{X}_{13}$ & Knowledge management \\
\hline & $\mathrm{X}_{10}$ & $\begin{array}{l}\text { Continuous support for the } \\
\text { development of a Lean } \\
\text { Construction production } \\
\text { system }\end{array}$ & & $\mathrm{X}_{14}$ & Logistic operations \\
\hline & $\mathrm{X}_{11}$ & $\begin{array}{l}\text { Focus in the Lean Construction } \\
\text { Philosophy }\end{array}$ & & $\mathrm{X}_{15}$ & Contractual management process \\
\hline & $\mathrm{X}_{12}$ & Business outcomes & & $\mathrm{X}_{16}$ & Implementation of a management system \\
\hline & tor: $V$ & x Environment (WorkEnv) & & $\mathrm{X}_{17}$ & Information systems \\
\hline \multirow{3}{*}{ 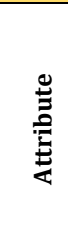 } & $\mathrm{x}_{6}$ & $\begin{array}{l}\text { Participation of people in the } \\
\text { construction of the work } \\
\text { environment }\end{array}$ & & $\mathrm{X}_{18}$ & $\begin{array}{l}\text { Project support with organizational } \\
\text { processes }\end{array}$ \\
\hline & $\mathrm{X}_{7}$ & $\begin{array}{l}\text { Interaction in the work } \\
\text { environment }\end{array}$ & & & \\
\hline & $\mathrm{X}_{8}$ & $\begin{array}{l}\text { Learning and training for } \\
\text { safety in workplace safety }\end{array}$ & & & \\
\hline
\end{tabular}

The quality of the information used in the model is verified by the validity of the FMs with the statistics, Table 2. That information was processed and obtained with the WarpPLS software. In the last column of the table we can see the acceptance criteria. For example, Cronbach's alpha index measures a high level of correlation between FMs. If Cronbach's alpha approaches 1.0, the more significant the reliability of the scale is. The acceptance criterion: values greater than 0.7 are sufficient to guarantee the reliability of the scale. Cronbach's alpha shows that FMs are adequately correlated, and each FM is accurately measuring a maturity condition. If Cronbach's Alpha is less than 0.7, a relaxed criterion is used, which is Composite Reliability, if it has a value $\geq 0.8$, the factor is accepted. (For details of the other indexes, refer to the doctoral thesis (Cano, 2019)) 
Table 2: Validity verify of the FMs in the SLC-EModel

\begin{tabular}{lcccccccc}
\hline \multicolumn{1}{c}{ Statistical } & TeamWork & WorkEnv & CommTM & SupporOp & LeaderSh & SPImprov & ProImpr & $\begin{array}{c}\text { criteria of } \\
\text { acceptance }\end{array}$ \\
\hline R-Squared & 0,539 & 0,469 & & 0,890 & 0,311 & 0,522 & 0,706 & $\geq 0.20$ \\
$\begin{array}{l}\text { Adjusted } \\
\text { R-Squared }\end{array}$ & 0,530 & 0,459 & & 0,887 & 0,305 & 0,513 & 0,698 & \\
$\begin{array}{l}\text { Composite } \\
\text { Reliability }\end{array}$ & 0,862 & 0,774 & 0,838 & 0,888 & 0,814 & 0,903 & 0,871 & $\geq 0.80^{*}$ \\
$\begin{array}{l}\text { Cronbach's } \\
\text { Alpha }\end{array}$ & 0,799 & 0,563 & 0,738 & 0,848 & 0,693 & 0,873 & 0,822 & $\geq 0.70$ \\
$\begin{array}{l}\text { Extracted } \\
\text { Average }\end{array}$ & 0,555 & 0,534 & 0,568 & 0,572 & 0,525 & 0,573 & 0,530 & $\geq 0.50$ \\
$\begin{array}{l}\text { Variance, AVE } \\
\text { Full }\end{array}$ & & & & & & & & \\
Collinearity, & 1,975 & 2,402 & 3,305 & 4,103 & 2,358 & 2,737 & 4,298 & $\leq 3.30$ \\
VIF & 0,542 & 0,476 & & 0,654 & 0,316 & 0,518 & 0,707 & $>0.00$ \\
Q-squared & $-2,154$ & $-1,075$ & $-0,940$ & $-1,044$ & $-1,487$ & $-0,991$ & $-1,353$ & $\leq 3.00$ \\
$\begin{array}{l}\text { Skewness } \\
\text { Kurtosis }\end{array}$ & 8,051 & 1,842 & 0,915 & 1,738 & 2,438 & 0,846 & 2,258 & $\leq 5.00 *$ \\
\hline
\end{tabular}

Model quality is verified with the fulfillment of 10 indicators, according to Table 3 . In the last column of the table we can see the acceptance criteria. The SEM presents an adequate level of adjustment that explains the consistency of the model, which reflects the behavior of the phenomenon studied. The model is shown in Figure 2 (Cano, 2019). The SEM is the way to validate the relationships between FMs and build the local maturity index (ILMi) for each FM. With the local indexes, the global maturity index (IGMo) is constructed. The IGMo requires a statistical model to operate the local results on the same scale to obtain it. This index represents the maturity of LC in the CPM.

Table 3: SEM performance results

\begin{tabular}{|c|c|c|}
\hline Index & Outcome & Acceptance criteria \\
\hline Average path coefficient (APC) & 0,394 & $\mathrm{P}<0,001$ \\
\hline Average R-squared (ARS) & 0,494 & $\mathrm{P}<0,001$ \\
\hline Average adjusted R-squared (AARS) & 0,485 & $\mathrm{P}<0,001$ \\
\hline Average block VIF (AVIF) & 1,481 & acceptable if $<=5$, ideally $<=3,3$ \\
\hline Average full collinearity VIF (AFVIF) & 2,998 & acceptable if $<=5$, ideally $<=3,3$ \\
\hline Tenenhaus GoF (GoF) & 0,522 & small $>=0.1$, medium $>=0,25$, large $>=0,36$ \\
\hline $\begin{array}{l}\text { Sympson's paradox ratio (SPR), R-squared } \\
\text { contribution ratio (RSCR) }\end{array}$ & 1,000 & acceptable if $>=0,7$, ideally $=1$ \\
\hline $\begin{array}{l}\text { Statistical suppression ratio (SSR), Nonlinear } \\
\text { bivariate causality direction ratio (NLBCDR) }\end{array}$ & 1,000 & acceptable if $>=0,7$ \\
\hline
\end{tabular}

\section{MeASUREMENT MODEL}

The measurement model is integrated by correlated attributes that explain each FM. Table 4 presents the equations for each FM.

$$
\xi=\Lambda_{\mathbf{x}} \mathbf{x}+\delta \quad \eta=\Lambda_{\mathbf{y}} \mathbf{y}+\epsilon
$$

$\boldsymbol{\Lambda}_{\mathbf{x}}$ : (Lamda) Factorial loads of the attributes. The x that explain exogenous FM, $\xi$. $\boldsymbol{\Lambda}_{\mathbf{y}}$ : (Lamda) Factorial loads of attributes. The and that explain the endogenous FM, $\eta$. $\xi$ : (Xi

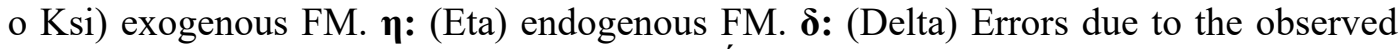
attributes x, related to the exogenous FM. є: (Épsilon) Errors due to attributes and related 
to endogenous FM.

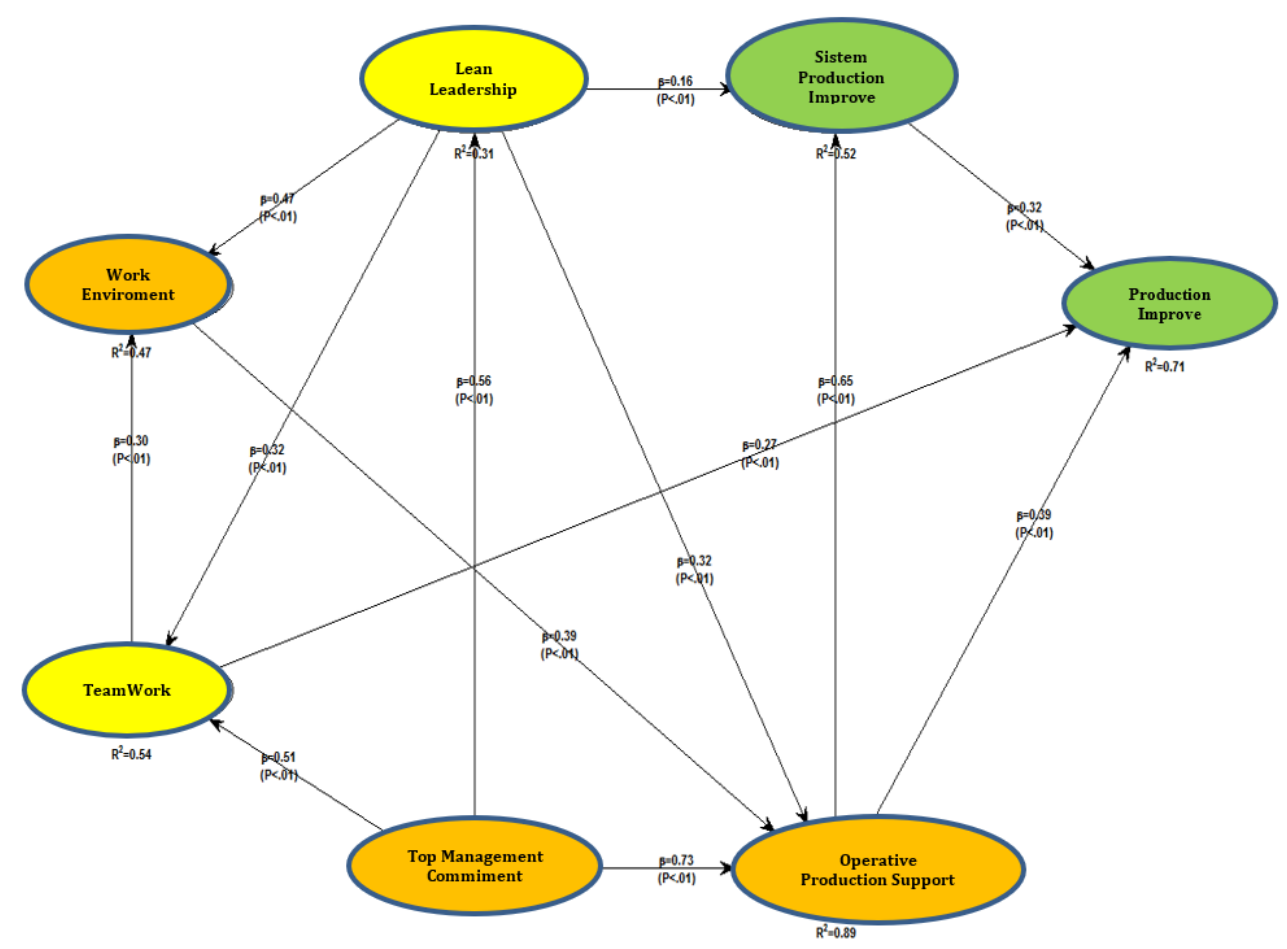

Figure 2: Representation of the relationships between the maturity factors

\section{StruCtURAL Model}

The structural model has the form:

$$
\boldsymbol{\eta}=\boldsymbol{\Gamma} \boldsymbol{\xi}+\mathbf{B} \boldsymbol{\eta}+\boldsymbol{\zeta}
$$

The structural model in the form of a matrix arrangement is represented in Figure 3. This form represents the associated matrices, where:

$\eta$ : (Eta) endogenous FM.

$\Gamma$ : (Gamma) Refers to the matrix q x r of regression coefficients between exogenous FM and endogenous FM variables.

$\xi:$ (Xi o Ksi) exogenous FM.

B: (Beta) It is a matrix of q x q of regression coefficients between endogenous FM.

$\zeta$ : (Zeta) Errors due to endogenous FM.

The matrix expression is developed with lowercase letters for the parameters of these matrices, which have the same interpretations as the previous ones.

$\gamma$ : Causal trajectory of an exogenous FM to an endogenous FM.

$\beta$ : Causal trajectory among endogenous FM. 
Table 4: Equations for each FM

\begin{tabular}{|c|c|c|c|c|c|}
\hline $\begin{array}{c}\text { Top } \\
\text { Management } \\
\text { Commitment }\end{array}$ & $\xi_{1}=\left[\lambda_{91}\right.$ & $\lambda_{101}$ & $\left.\lambda_{111} \quad \lambda_{121}\right]\left[\begin{array}{c}x_{9} \\
x_{10} \\
x_{11} \\
x_{12}\end{array}\right]+$ & $+\left[\begin{array}{c}\delta_{9} \\
\delta_{10} \\
\delta_{11} \\
\delta_{12}\end{array}\right]$ & \\
\hline Leadership & $\eta_{1}=\left[\lambda_{192}\right.$ & $\lambda_{202}$ & $\left.\lambda_{212} \quad \lambda_{222}\right]\left[\begin{array}{l}x_{19} \\
x_{20} \\
x_{21} \\
x_{22}\end{array}\right]+$ & $+\left[\begin{array}{l}\epsilon_{19} \\
\epsilon_{20} \\
\epsilon_{21} \\
\epsilon_{22}\end{array}\right]$ & \\
\hline $\begin{array}{l}\text { Operative } \\
\text { Production } \\
\text { Support }\end{array}$ & $\eta_{2}=\left[\lambda_{13}\right.$ & $\lambda_{23}$ & $\left.\begin{array}{lll}\lambda_{33} & \lambda_{43} & \lambda_{53}\end{array}\right]\left[\begin{array}{l}\lambda_{1} \\
\lambda_{2} \\
\lambda_{3} \\
\lambda_{4} \\
\lambda_{5}\end{array}\right]$ & $+\left[\begin{array}{l}\epsilon_{1} \\
\epsilon_{2} \\
\epsilon_{3} \\
\epsilon_{4} \\
\epsilon_{5}\end{array}\right]$ & \\
\hline Team Work & $\eta_{3}=\left[\begin{array}{ll}\lambda_{133} & \lambda_{143}\end{array}\right.$ & $\lambda_{153}$ & $\left.\begin{array}{lll}\lambda_{163} & \lambda_{173} & \lambda_{183}\end{array}\right]$ & {$\left[\begin{array}{l}x_{13} \\
x_{14} \\
x_{15} \\
x_{16} \\
x_{17} \\
x_{18}\end{array}\right]+$} & $+\left[\begin{array}{l}\epsilon_{13} \\
\epsilon_{14} \\
\epsilon_{15} \\
\epsilon_{16} \\
\epsilon_{17} \\
\epsilon_{18}\end{array}\right]$ \\
\hline
\end{tabular}

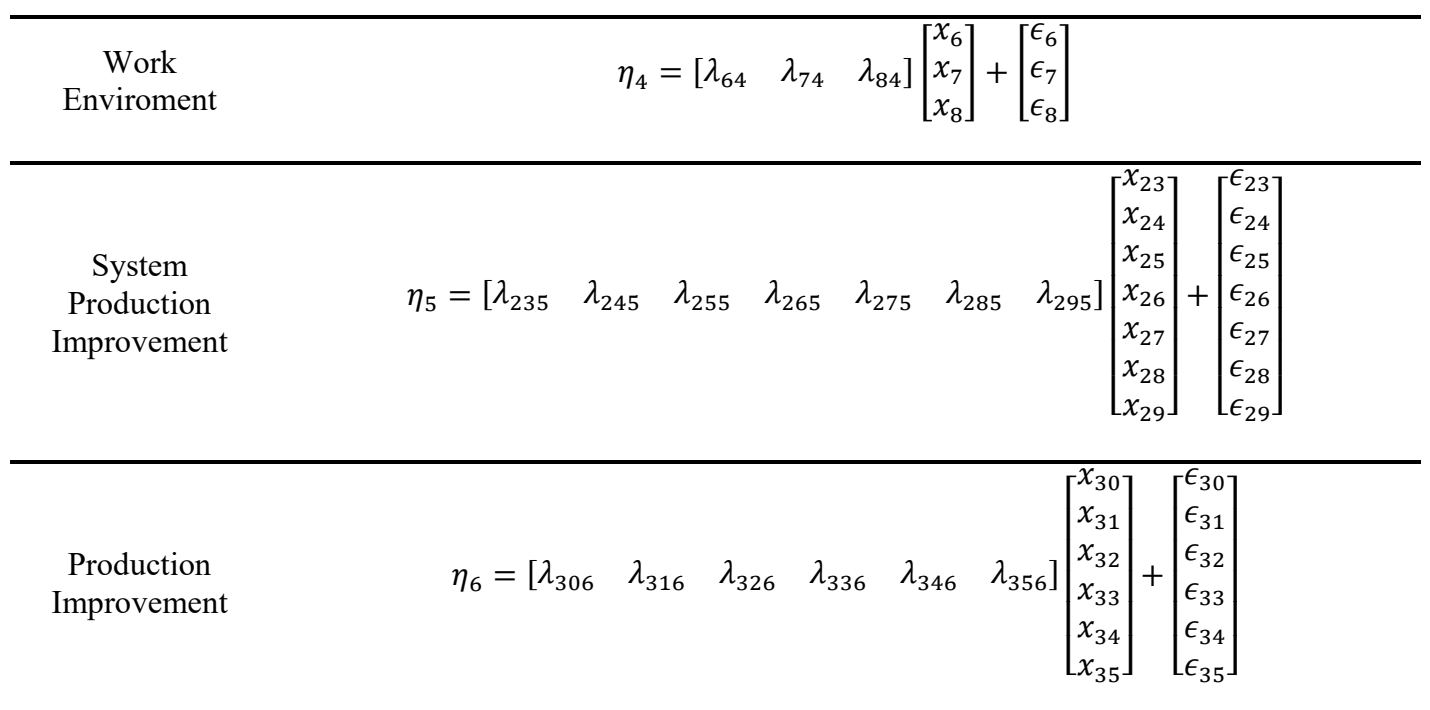

$$
\left[\begin{array}{l}
\eta_{1} \\
\eta_{2} \\
\eta_{3} \\
\eta_{4} \\
\eta_{5} \\
\eta_{6}
\end{array}\right]=\left[\begin{array}{l}
\gamma_{11} \\
\gamma_{12} \\
\gamma_{13}
\end{array}\right] \times \xi_{1}+\left[\begin{array}{cccccc}
0 & 0 & 0 & 0 & 0 & 0 \\
\beta_{21} & 0 & 0 & 0 & 0 & 0 \\
\beta_{31} & 0 & 0 & \beta_{34} & 0 & 0 \\
\beta_{41} & \beta_{42} & 0 & 0 & 0 & 0 \\
\beta_{51} & 0 & 0 & 0 & 0 & 0 \\
0 & \beta_{62} & \beta_{63} & 0 & \beta_{65} & 0
\end{array}\right] \times\left[\begin{array}{c}
\eta_{1} \\
\eta_{2} \\
\eta_{3} \\
\eta_{4} \\
\eta_{5} \\
\eta_{6}
\end{array}\right]+\left[\begin{array}{c}
\zeta_{1} \\
\zeta_{2} \\
\zeta_{3} \\
\zeta_{4} \\
\zeta_{5} \\
\zeta_{6}
\end{array}\right]
$$

Figure 3: Structural model matrix 


\section{SCHEMA OF APPLICATION OF SLC-MODEL IN THE CPM}

The SLC-EModel, requires a maturity evaluation that is expressed through the ILMi and IGMo indexes so that once the new maturity objective is defined, the maturity strategy allows the identification of the attributes that must be acted upon to propose an intervention according to the resources available to the organization. Figure 3 shows a basic flow to maturity evolution from the evaluation of the current state.

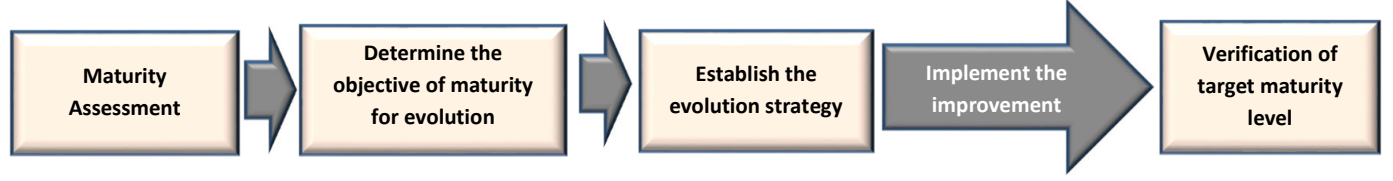

Figure 3: Basic flow of application of SLC-EModel

\section{MATURITY LOCAL INDEX (IGLI) OF LC IN THE CPM}

The indexes obtained as a result of the development of the statistical model are presented in Table 5. The value of each ILM is calculated up two routes. The first derived from the specific weights contributed by the correlated attributes which explain the maturity of each factor independently, and second, by the effect of the maturity from related factors that directly or indirectly influence the maturity of a factor.

Table 5: Maturity local Indexes for each FM

\begin{tabular}{|c|c|}
\hline$I L M_{1}=Y_{\text {CommTM }}$ & $Y_{1}=\left(0,277 * x_{9}+0,278 * x_{10}+0,240 * x_{11}+0,205 * x_{12}\right)$ \\
\hline$I L M_{2}=Y_{\text {LeaderSh }}$ & $Y_{2}=\left(0,268 * x_{19}+0,266 * x_{20}+0,253 * x_{21}+0,214 * x_{22}\right)+\left(0,104 * I L M_{1}\right)$ \\
\hline$I L M_{3}=Y_{\text {TeamWork }}$ & $\begin{array}{c}Y_{3}=\left(0,192 * x_{1}+0,206 * x_{2}+0,213 * x_{3}+0,198 * x_{4}+0,191 * x_{5}\right) \\
+\left(0,095 * I L M_{1}+0,059 * I L M_{2}\right)\end{array}$ \\
\hline$I L M_{4}=Y_{\text {WorkEnv }}$ & $Y_{4}=\left(0,337 * x_{6}+0,332 * x_{7}+0,331 * x_{8}\right)+\left(0,087 * I L M_{2}+0,056 * I L M_{3}\right)$ \\
\hline$I L M_{5}=Y_{\text {Supporop }}$ & $\begin{array}{c}Y_{5}=\left(0,160 * x_{13}+0,180 * x_{14}+0,171 * x_{15}+0,161 * x_{16}+0,184 * x_{17}+0,144\right. \\
\left.* x_{18}\right)+\left(0,136 * I L M_{1}+0,059 * I L M_{2}+0,072 * I L M_{4}\right)\end{array}$ \\
\hline$I L M_{6}=Y_{S P I m p r o v}$ & $\begin{array}{c}Y_{6}=\left(0,157 * x_{23}+0,152 * x_{24}+0,152 * x_{25}+0,148 * x_{26}+0,143 * x_{27}+0,134\right. \\
\left.* x_{28}+0,114 * x_{29}\right)+\left(0,030 * I L M_{2}+0,121 * I L M_{5}\right)\end{array}$ \\
\hline $\operatorname{ILM}_{7}=Y_{\text {ProImpro }}$ & $\begin{array}{c}Y_{7}=\left(0,175 * x_{30}+0,170 * x_{31}+0,169 * x_{32}+0,168 * x_{33}+0,161 * x_{34}+0,157\right. \\
\left.* x_{35}\right)+\left(0,050 * I L M_{3}+0,072 * I L M_{5}+0,059 * I L M_{6}\right)\end{array}$ \\
\hline
\end{tabular}

Figure 4 presents the graphical representation of reference values of maturity according to the equation for each of the factors. Note that the graphical representation of these reference levels is not symmetric. Its particular form is due to the FM influence on another FM later in the flow of maturity. 


\section{GLOBAL MATURITY INDEX (IGMo) OF LC IN THE CPM}

The IGMo is built from the contribution of the factor loads of all the ILMi of each FM. This local rating is integrated into a statistical model specifically designed to obtain a general index. The equation for the IGMo is presented below. A scheme for getting IGMo from ILMi is shown in Figure 5.

$$
\begin{array}{rl}
I G M_{o}=0,154 * & I L M_{1}+0,134 * I L M_{2}+0,122 * I L M_{3}+0,142 * I L M_{4}+0,151 * I L M_{5}+0,132 * I L M_{6} \\
& +0,165 * I L M_{7}
\end{array}
$$

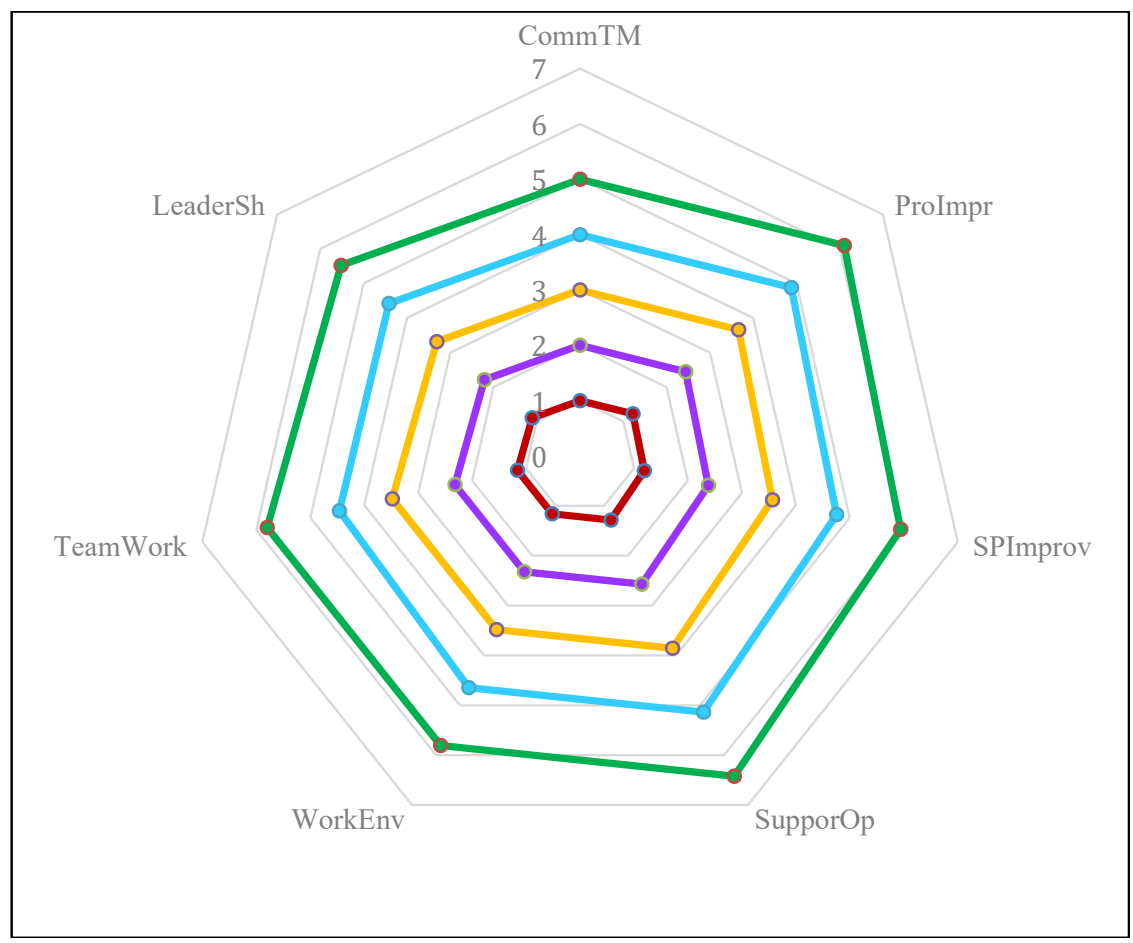

Figure 4: Reference maturity levels

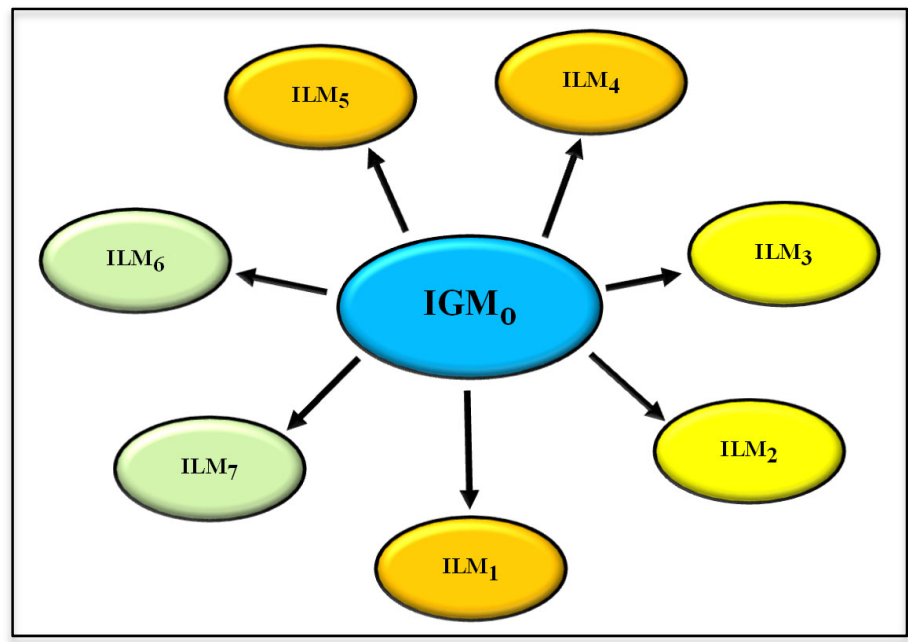

Figure 5: Scheme for obtaining the Global Maturity Index 
This model was designed to assess the maturity of LC in the CPM. However, its development allows it to be adapted and applied to other contexts and production processes. The SLC-EModel has the ability to explain the phenomenon of maturity in any productive sector, considering that any production system has the same categories as those defined in it.

For the implementation of the model, it is required to apply in the field the for attributes assessment. This tool is called the SLC-MAET. Due to the high volume of information to evaluate the model, a software tool must be developed to provide the maturity rating. Both the evaluation and the analysis of the data are carried out in an environment of organizational self-evaluation, which allows the evolution strategy to be jointly built with all work teams at all organizational levels involved in LC maturity. It is recommended to carry out an annual evaluation of maturity; in this way, the selfevaluation process permanently induces a continuous and conscious improvement to the production system. The assessment should consider different ways of obtaining information such as surveys, focus groups, interviews, and data collection, as specified in the model.

\section{CONCLUSION}

The SLC-EModel is made up of two models, a maturity model and an evolution strategy. Its practical value is that it promotes a self-evaluation process that evaluates the current state of maturity so that, from recognizing the strengths and weaknesses of the organization concerning a standard, the evolution is guided by a route of improvement focused on a strategic goal of maturity.

In the project production system, people are the essential component for the production process. In the construction project, all operations are carried out with people who constitute work teams, and the team's work builds their work environments. In this way, companies must concentrate their efforts on the formation of human capital to build an LC culture.

The production process of the construction project requires people trained with attitude and willingness to work and improve continuously, a production system, and organizational operations at the service of the project that effectively contribute to the production flow.

To adopt and apply manufacturing technologies in the construction industry, a better understanding of innovation management practices is required. An evolution model must be a simple tool to apply, which systemically includes people at different levels of the organization.

The authenticity of the elements identified and the relationships between them are ensured since the results broadly represent the phenomenon of maturity observed objectively. The results of the SEM clearly and broadly represent the constructs to which it refers.

\section{RESEARCH LIMITATIONS}

To apply the model, it is necessary to develop the SLC-MAET, the attribute evaluation tool. This tool requires consultation with LC experts to select the appropriate characteristics for each attribute and to construct the rubrics with which the selfevaluation team will orient the evolution. In the same way, the validation of the selection of characteristics for the evaluation of attributes in the field it is required. 


\section{ACKNOWLEDGMENTS}

Authors express their gratitude to Universidad del Valle for the sponsorship and to all LC professionals who participated in this research.

\section{REFERENCES}

Andersen, E. S., and Jessen, S. A. (2003). Project maturity in organisations. Int. J. Project Management, 21(6), 457-461. https://doi.org/10.1016/S0263-7863(02)00088-1

Bashir, A. M., Suresh, S., Proverbs, D., and Gameson, R. (2011). A critical, theoretical, review of the impacts of lean construction tools in reducing accidents on construction sites. Association of Researchers in Construction Management, ARCOM 2011 - Proc. 27th Annual Conference, 1(September), 249-258.

Cano, S. (2019). Modelo de Evolución de la Madurez de Lean Construction en la Gestión de Producción de Proyectos de Construcción (SLC-EModel). Universidad del Valle. Retrieved from http://hdl.handle.net/10893/13948

Cano, S., and Rivera, L. (2015). Modelo Sistémico de la Madurez en la Aplicación de Lean en la Gestión de Proyectos de Construcción. Sibragec Elagec 2015, (Lc), 649656. Retrieved from http://www.infohab.org.br/sibraelagec2015/artigos/SIBRAGECELAGEC_2015_submission_82.pdf

Chandra, H. P. (2015). Structural equation model for investigating risk factors affecting project success in Surabaya. Procedia Engineering, 125, 53-59. https://doi.org/10.1016/j.proeng.2015.11.009

Costa Neto, E. N., Sartori Filho, H., Santiago, M. V, dos Santos, P. R., Santana, P. L., and da Silva, R. B. (2015). Evaluation of the use of the principles of lean construction in two companies in the construction sector in the municipality of Rondonópolis-MT. Espacios, 36(19), 11.

Cupani, M. (2012). Análisis de Ecuaciones Estructurales: conceptos, etapas de desarrollo y un ejemplo de aplicación. Revista Tesis, 136-156.

Ehsan, N., Perwaiz, A., Arif, J., Mirza, E., and Ishaque, A. (2010). CMMI/SPICE based process improvement. 5th IEEE International Conference on Management of Innovation and Technology, ICMIT2010, 859-862. https://doi.org/10.1109/ICMIT.2010.5492803

García, J. L. (2011). Factores relacionados con el éxito del mantenimiento productivo total Factors related with success of total productive maintenance. Rev. Fac. Ing. Univ, Antioquia, 129-140.

Ibbs, C. W., and Kwak, Y. H. (2000). Assessing Project Management Maturity. Project Management Journal, 31(1), 32-43. https://doi.org/10.1109/TEM.2005.861802

Ramirez, J. M. (2009). Planeación de la implantación de sistemas de información en las PYME mexicanas Jesús Marcelo Ramírez Arias. Primer Congreso Internacional En México Sobre La MIPYME: El Impacto de La Investigación Académica En El Desarrollo de La MIPYME., 1-19.

Vieira, H. F. (2006). Logística Aplicada à Construção Civil (1 Edición). Editora Pini Ltda. Weston, R., and Gore, P. A. (2006). A Brief Guide to Structural Equation Modeling. The $\begin{array}{llll}\text { Counseling } \quad \text { Psychologist, } & \text { 34(5), }\end{array}$ https://doi.org/10.1177/0011000006286345 